\title{
DEVELOPMENT AND VALIDATION OF A NEW HPLC BIOANALYTICAL INTERNAL STANDARD METHOD FOR THE ANALYSIS OF REMDESIVIRIN HUMAN PLASMA
}

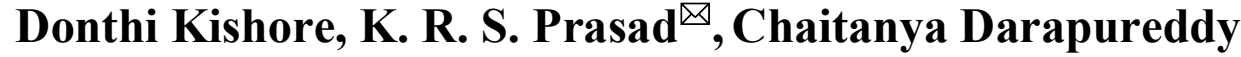 \\ and R. S. CH. Phani
}

Department of Chemistry, K.L. University, Vaddeswaram-522 502, Andhra Pradesh, India

${ }^{\bowtie}$ Corresponding Author: krsprasad47@gmail.com

\begin{abstract}
Remdesivir (RMDSVR) is a pro-drug of an ATP analog, with antiviral activity against RNA viruses. In 2016 RMDSVR is used in the treatment of Ebola and 2017 RMDSVR was tested against SARS-CoV-2. The HPLC analysis was performed on the Agilent 1100 series HPLC with Quaternary G1311 A pump, ChromosilC18 column $(250 \times 4.6 \mathrm{~mm}, 5 \mu)$ column, with a mixture of Acetonitrile, Methanol and 0.1\% OPA in the ratio of 65:30:5 (v/v) as the mobile phase, at $0.8 \mathrm{~mL} / \mathrm{min}$ flow rate and UV detection at $272 \mathrm{~nm}$. Abacavir (ABVR) is considered an internal standard and the retention time was observed at $6.0 \mathrm{~min}$ and $9.1 \mathrm{~min}$ for RMDSVR and ABVR respectively. The calibration curve was obtained linearly in the concentration range of $10-70 \mathrm{ng} / \mathrm{mL}$. the method was validated and all the validated parameters were within the acceptable limit confirms that the method is suitable for the analysis of RMDSVR in spiked human plasma.

Keywords: RP-HPLC, Internal Standard Method, Remdesivir, Abacavir, Bio-analytical Method and ICH Guidelines.
\end{abstract}

RASĀYAN J. Chem., Vol. 14, No.4, 2021

\section{INTRODUCTION}

Bio Analytical methods development and validation play vital roles in the clinical trials to determine the drug or analyte quantitatively in biological matrix. The quality of the bio-analytical data depends on the quality and accuracy of the bio-analytical studies. Hence validation of the bioanalytical methods is established and disseminated to the pharmaceutical community. ${ }^{1-2}$

Remdesivir (RMDSVR) is a pro-drug of an ATP analog, with antiviral activity against a variety of RNA viruses. In the year 2016 RMDSVR is used in the treatment of Ebola and 2017, RMDSVR was tested against the coronavirus family of viruses like SARS-CoV-2. RMDSVR was granted an FDA Emergency Use Authorization on 1 May 2020. This is not the same as an FDA approval. ${ }^{3}$

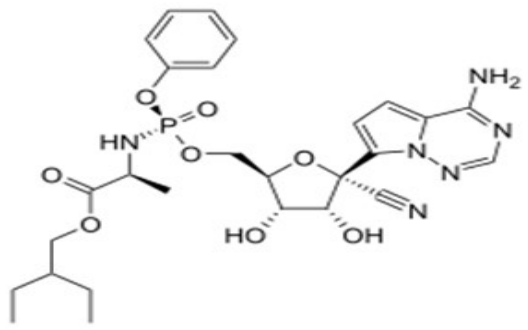

Fig.-1: Structure of Remdesivir

\section{Instrumentation}

\section{EXPERIMENTAL}

Agilent 1100 series HPLC equipped with Quaternary pump (G1311 A), thermostat column temperature control (COLCOM G1316A), Thermostatic autosampler (G 1329A) with a sample volume of $0.1-1500$ $\mu \mathrm{L}$ and UV detector ( $\mathrm{G} 1314 \mathrm{~A}$ ) was used the separation and analysis of RMDSVR and ABVR in Rasayan J. Chem., 14(4), 2639-2644(2021)

http://doi.org/10.31788/RJC.2021.1446373

This work is licensed under a CC BY 4.0 license. 
biological samples. Agilent chem station LC software was used for the integration of chromatogram and operation of the instrument. Chromosil C18 (250 X $4.6 \mathrm{~mm}, 5 \mu)$ column was used for the separation of compounds.

\section{Chemicals and Solvents}

HPLC Grade Methanol, Acetonitrile, Ortho Phosphoric Acid (OPA) and water were procured from Fisher Scientific PVT LTD, Mumbai.

\section{Preparation of Mobile Phase}

An accurately measured mobile phase composition such as acetonitrile (65\%), methanol (30\%) and $0.1 \%$ OPA ( $5 \%$ ) was mixed to ensure the homogeneous solvent using ultra sonicator and filtered through $0.45 \mu$ filters using vacuum filtration. Then the prepared mobile phase solution was stored in an amber color bottle for further use.

\section{Preparation of Diluent}

In the preparation of standard stock solutions, the mobile phase is used as a diluent in the analysis.

\section{Collection and Preparation of Plasma}

The healthy human blood sample was collected in heparinized tubes from the diagnostic lab. Then the collected blood sample was centrifuged for $5 \mathrm{~min}$ at $5000 \mathrm{rpm}$ at room temperature for the separation of plasma from the blood. The separated plasma was stored at $-30^{\circ} \mathrm{C}$ till further use.

\section{Preparation of Sample Solution}

Different organic extraction solvents such as methanol, acetonitrile, diethyl ether, chloroform, and dichloromethane were used in single or in combination with each other for extraction of drug and internal standards from plasma. The solvent composition that extracts the analytes with high recovery was selected for extraction of analytes from plasma. The extraction of analytes was carried by following liquid-liquid extraction.

The analytes RMDSVR and ABVR at known concentration were premixed with plasma and were extracted using Diethyl ether and methanol in the ratio of 50:50 (v/v) as extraction solvent. The blank sample was prepared from un-spiked plasma. Then it was vortex for $1 \mathrm{~min}$ and then centrifuged at $4^{\circ} \mathrm{C}$ at 5000rpm. The Supernatant solution was separated and kept in an HPLC vial.

\section{Preparation of Calibration Solutions ${ }^{4-6}$}

The calibration curve dilutions were prepared by adding $0.1 \mathrm{~mL}$ of standard drug solution of known concentrations to $0.9 \mathrm{~mL}$ of blank human plasma to get $10,20,30,40,50,60$, and $70 \mathrm{ng} / \mathrm{mL}$ of RMDSVR. The concentration of internal standard was maintained at a concentration of $40 \mu \mathrm{g} / \mathrm{mL}$.

\section{Method Development and Optimized Conditions ${ }^{7-16}$}

The present study aims to develop a sensitive analytical condition to identify and quantify the analytes at a very low concentration. The chromatography parameters such as nature of the columns, mobile phase composition and flow rate, and wavelength of the detector were optimized during the method development. The iso-absorption wavelength was selected as detector wavelength in the study. The conditions that produce the best separation with acceptable system suitable conditions were further studied for validation and the optimized conditions were given in Table-1.

\begin{tabular}{c|c|c}
\multicolumn{3}{|c}{ Table-1: Optimized Chromatographic Conditions } \\
\hline S. No. & Condition & Results \\
\hline 1 & Mobile phase & $\begin{array}{l}\text { Acetonitrile, Methanol and } 0.1 \% \\
\text { OPA in the ratio of } 65: 30: 5(\mathrm{v} / \mathrm{v})\end{array}$ \\
\hline 2 & Pump mode & Isocratic \\
\hline 3 & $\mathrm{pH}$ & 5.2 \\
\hline 4 & Diluents & Mobile phase \\
\hline 5 & Column & Chromosil C18 Column $(250 \mathrm{X}$ \\
\hline \multicolumn{2}{|c}{2640}
\end{tabular}


RASĀYAN J. Chem.

Vol. 14 | No. 4 |2639-2644| October- December | 2021

\begin{tabular}{c|c|c}
\hline & & $4.6 \mathrm{~mm}, 5 \mu)$ column \\
\hline 6 & Column Temp & Ambient \\
\hline 7 & Wavelength & $272 \mathrm{~nm}$ \\
\hline 8 & Injection Volume & $20 \mu \mathrm{l}$ \\
\hline 9 & Flow rate & $0.8 \mathrm{~mL} / \mathrm{min}$ \\
\hline 10 & Run time & $20 \mathrm{~min}$ \\
\hline 11 & Calibration range & $10-70 \mathrm{ng} / \mathrm{mL}$ \\
\hline
\end{tabular}

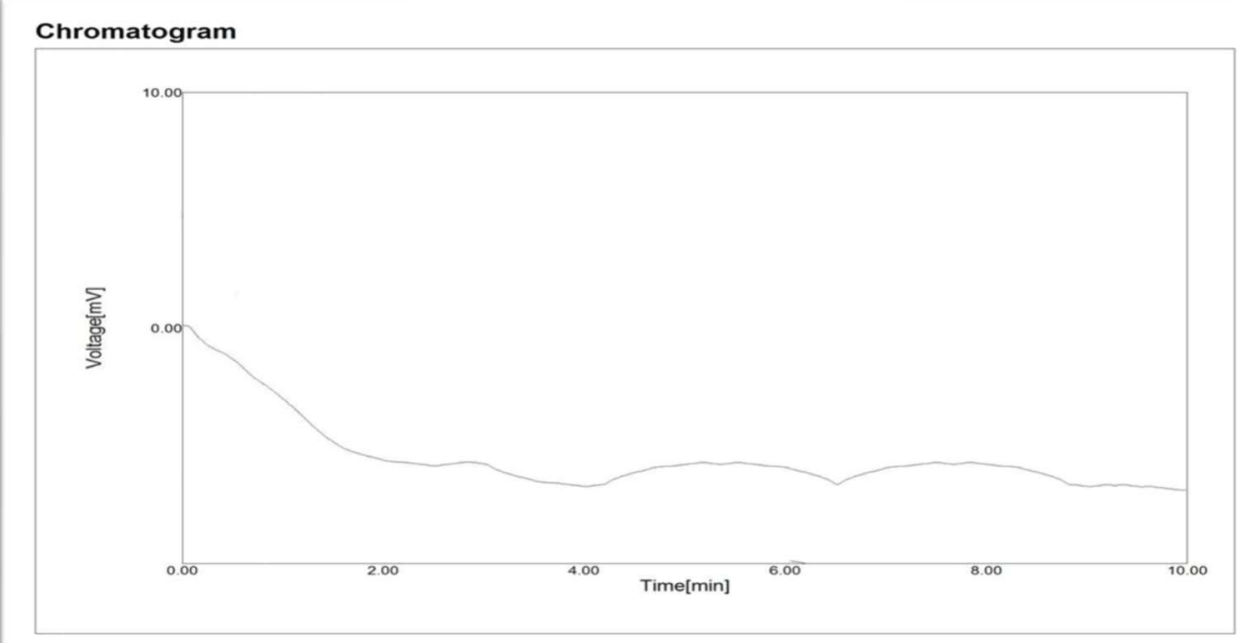

Fig.-2: Blank Chromatogram of Plasma with Diluents and further subjected to Liquid-liquid Extraction

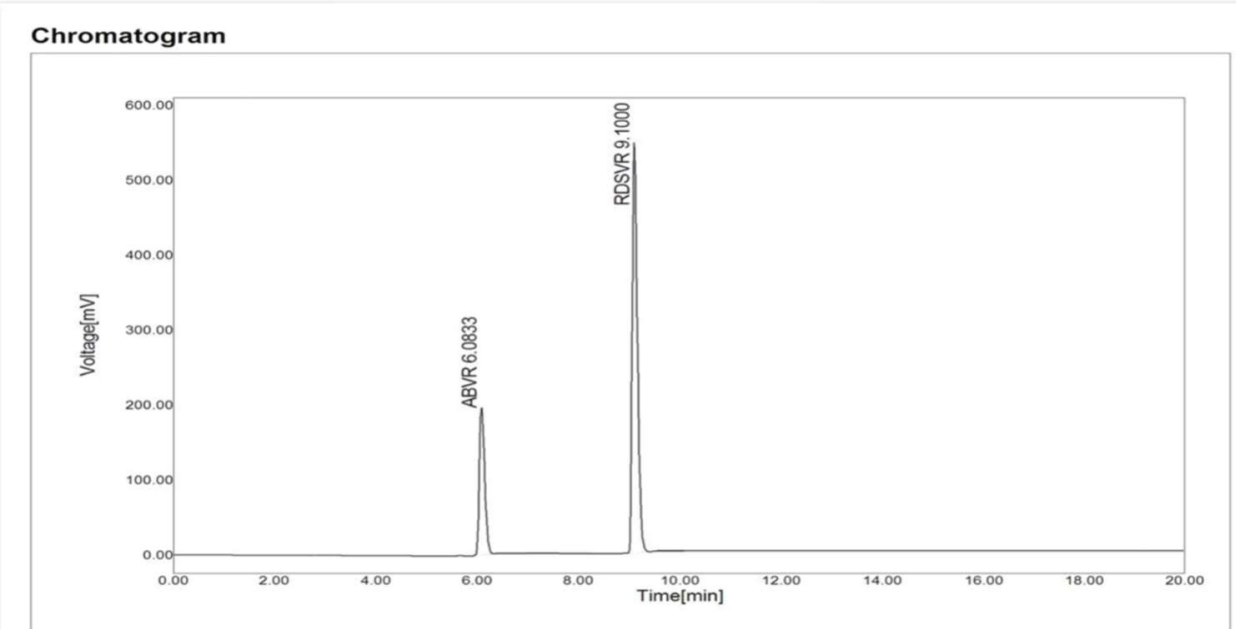

Fig.-3: System Suitability Chromatogram of Plasma spiked Drug of RMDSVR with ABVR (IS) no interfering

Method Validation ${ }^{17-34}$ endogenous after Liquid-liquid Extraction

The system suitability was studied at the middle of quantification (MQC) of $40 \mathrm{ng} / \mathrm{mL}$ by comparing blank responses of plasma. Accuracy was estimated as the mean RE while the precision was measured in terms of RSD. For each of the above validation tests, the analysis was performed at three QC concentrations (low, medium and high), with six determinations for each concentration. The stability of RMDSVR in human plasma was evaluated under different conditions viz. three freeze-thaw cycles, stability of long term for 30 days and stability of short term at room temperature for $6 \mathrm{~h}$. All the validation stability studies were performed at LQC, MQC and HQC concentrations. The obtained results were compared with the nominal concentration of the analytes. 
RASĀYAN J. Chem.

Vol. 14 | No. 4 |2639-2644| October- December | 2021

Table -2: Linearity Test Result of RMDSVR

\begin{tabular}{c|c|c|c|c|c}
\hline \multirow{2}{*}{ S. No. } & \multirow{2}{*}{$\begin{array}{c}\text { Concentration in } \\
\mathrm{ng} / \mathrm{mL}\end{array}$} & \multicolumn{2}{|c|}{ Peak Area observed for } & \multirow{2}{*}{$\begin{array}{c}\text { Ratio of } \\
\text { Standard/IS }\end{array}$} & \multirow{2}{*}{ Sample Id } \\
\cline { 3 - 4 } & 10 & RMDSVR - Standard & ABVR - IS & 1.41 & RMDSVR-1 \\
\hline 1 & 20 & 28324 & 20052 & 1.45 & RMDSVR-2 \\
\hline 2 & 30 & 32256 & 22184 & 1.48 & RMDSVR-3 \\
\hline 3 & 40 & 36502 & 24567 & 1.52 & RMDSVR-4 \\
\hline 4 & 50 & 40958 & 26906 & 1.55 & RMDSVR-5 \\
\hline 5 & 60 & 44230 & 28459 & 1.58 & RMDSVR-6 \\
\hline 6 & 70 & 48452 & 30548 & 1.62 & RMDSVR-7 \\
\hline 7 & 52780 & 32442 & & \\
\hline
\end{tabular}

$\mathrm{CC}=0.9991$, Slope:291.16, $\mathrm{IC}=1.37$

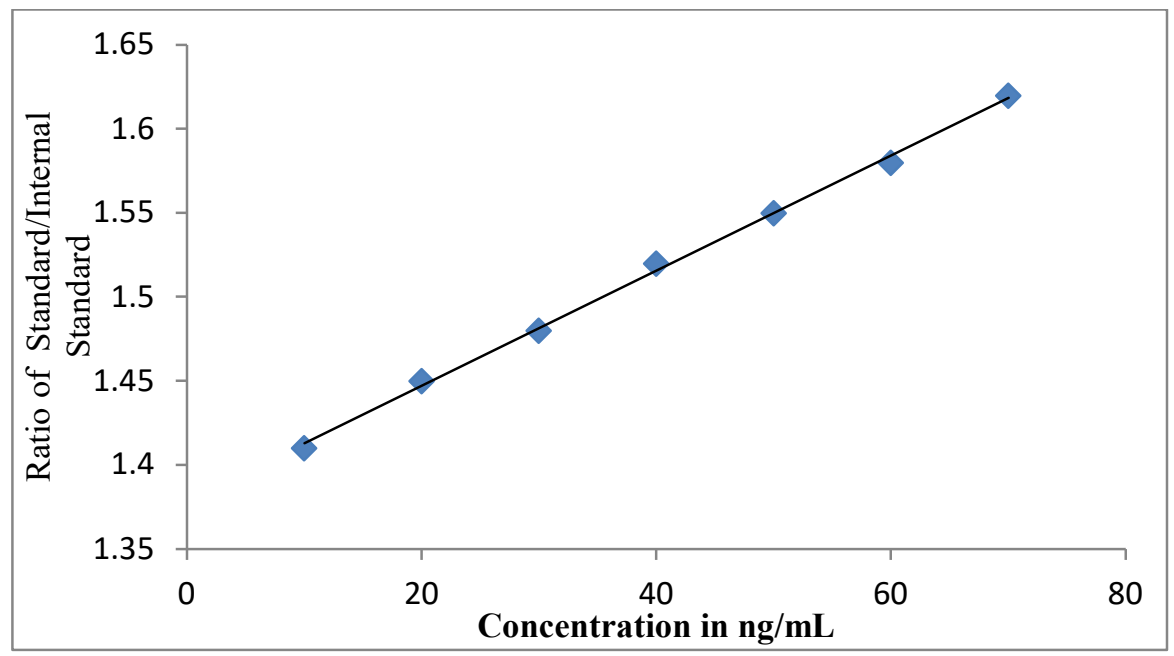

Fig.-4: Calibration Curve which Ratio of RMDSVR to Internal Standard ABVR

Table -3: RMDSVR results of Precision and Recovery study with various QC concentrations:

\begin{tabular}{|c|c|c|c|c|c|}
\hline S.No. & Parameter & Concentration & $\begin{array}{l}\% \text { of Drug } \\
\text { Estimated }\end{array}$ & $\begin{array}{l}\text { Standard } \\
\text { deviation }\end{array}$ & Accuracy $(\%)$ \\
\hline 1 & \multirow{3}{*}{$\begin{array}{l}\text { Intraday } \\
\text { Precision }\end{array}$} & HQC & $99.2-99.5$ & 0.88 & 95.9 \\
\hline 2 & & MQC & $98.9-99.8$ & 0.64 & 99.2 \\
\hline 3 & & LQC & $99.4-100.2$ & 0.26 & 100.2 \\
\hline 4 & \multirow{3}{*}{ InterdayPrecision } & HQC & 99.4-100.5 & 0.85 & 99.8 \\
\hline 5 & & MQC & $99.0-99.6$ & 0.42 & 99.4 \\
\hline 6 & & $\mathrm{LQC}$ & $99.8-100.8$ & 0.35 & 100.6 \\
\hline 7 & \multirow{3}{*}{ Recovery } & $\mathrm{HQC}$ & $99.5-100.4$ & 0.56 & 99.2 \\
\hline 8 & & MQC & $99.8-100.5$ & 0.28 & 99.8 \\
\hline 9 & & $\mathrm{LQC}$ & $99.5-101.2$ & 0.12 & 100.5 \\
\hline
\end{tabular}

Table -4: RMDSVR Results of Stability Study with Various QC Concentrations

\begin{tabular}{|c|c|c|c|c|c|}
\hline S.No. & Parameter & Concentration & $\begin{array}{l}\text { Percentage of } \\
\text { Drug Estimated }\end{array}$ & $\begin{array}{l}\text { Standard } \\
\text { deviation }\end{array}$ & Accuracy $(\%)$ \\
\hline 1 & \multirow{3}{*}{$\begin{array}{ll}\text { Short } & \text { term } \\
\text { Stability } & \end{array}$} & HQC & $99.6-100.2$ & 0.85 & 99.4 \\
\hline 2 & & MQC & $99.0-100.5$ & 0.69 & 99.9 \\
\hline 3 & & LQC & $99.8-100.8$ & 0.36 & 100.2 \\
\hline 4 & \multirow{3}{*}{$\begin{array}{l}\text { Long term } \\
\text { Stability }\end{array}$} & $\mathrm{HQC}$ & $98.2-99.6$ & 0.74 & 99.5 \\
\hline 5 & & MQC & 99.6- 100.5 & 0.52 & 100.2 \\
\hline 6 & & LQC & $99.9-100.8$ & 0.45 & 100.5 \\
\hline 7 & \multirow{3}{*}{$\begin{array}{l}\text { Freeze Thaw } \\
\text { Stability }\end{array}$} & $\mathrm{HQC}$ & $98.5-99.9$ & 0.96 & 99.5 \\
\hline 8 & & MQC & $99.5-100.6$ & 0.52 & 100.2 \\
\hline 9 & & $\mathrm{LQC}$ & $99.6-100.4$ & 0.29 & 100.6 \\
\hline
\end{tabular}




\section{RESULTS AND DISCUSSION}

The optimization was achieved at a mobile phase composition of acetonitrile, methanol and $0.1 \%$ OPA in the ratio of 65:30:5 (V/V), pH 5.2 as mobile phase at a flow rate of $0.8 \mathrm{~mL} / \mathrm{min}$ and UV detection at 272 $\mathrm{nm}$. Separation was achieved on Hypersil, C18 column (250 X $4.6 \mathrm{~mm}, 5 \mu)$ at ambient temperature and analysis was completed within 20 min run time. The retention was found to be $9.1 \mathrm{~min}$ for RMDSVR and $6.0 \mathrm{~min}$ for ABVR. The optimized chromatography conditions are presented in Table.1 and the chromatograms of blank and system suitability are shown in Fig.-2 and 3.

All analytes eluted rapidly with good resolution within $10.0 \mathrm{~min}$ without any interfering of plasma matrix components with the analyte peaks. Peaks shape and retention time (Rt) were found to be the same as that of pure standards.

The linearity of the method was evaluated at seven concentration ranges including the LQC. The calibration curves were found to be linear in the range 10-70 ng/ mL, with a correlation coefficient $\left(\mathrm{r}^{2}\right)$ of 0.9991 for RMDSVR. The data of calculated calibration standards are presented in Table.2. The linear calibration graph is shown in Figure.4. Recovery and stability samples were calculated from the resulting area ratio and the regression equation of the calibration curve. The lower limits of quantification (LLOQs) under the optimized conditions were $10 \mathrm{ng} / \mathrm{mL}$ for both drugs, which was determined from the visual method of detection.

The precision evaluation was assessed by repeated analysis of plasma samples containing different concentrations of RMDSVR with IS on separate occasions. Six replicates of LQC, MQC and HQC samples. Recovery of RMDSVR is evaluated by comparing mean analyte responses of six extracted samples of LQC, MQC and HQC samples. The Intraday Precision, Interday Precision, recovery of RMDSVR showed in Table-3.

Long term, short term and freeze-thaw stability studies were performed to evaluate the stability of RMDSVR in plasma. The results are shown in Table.4. The outcomes of other parameters like precision, accuracy, reproducibility, the effect of potentially interfering drugs, dilution integrity, were found to be within the acceptance criteria as per ICH and USFDA guidelines.

\section{CONCLUSION}

A simple, sensitive, accurate and precise RP-HPLC method was developed and validated for the estimation of RMDSVR in plasma with ABVR as an internal standard in plasma. The present method was employed with liquid-liquid extraction of the plasma spiked drug and successfully validated. The results of all validation and stability studies were found in the acceptable range of recovery. The developed RPHPLC method is efficient and can be used in pharmacokinetics studies as well as in the monitoring of the investigated RMDSVR in biological samples like body fluids.

\section{REFERENCES}

1. T. Baranovich, S.S. Wong, J. Armstrong, H. Marjuki, R.J. Webby, R.G. Webster and E.A. Govorkova, Journal of Virology, 87(7), 3741(2013), https://doi.org/10.1128/JVI.02346-12

2. Y.X. Du and X.P. Chen, Clinical Pharmacology and Therapeutics, 108, 190(2020), https://doi.org/10.1002/cpt.1844

3. K. Shiraki, and T. Daikoku, Pharmacology \& Therapeutics, 209, 107512(2020), https://doi.org/10.1016/j.pharmthera.2020.107512

4. Zoe Fox, Ulrik B. Dragsted, Jan Gerstoft, Andrew N. Phillips, Jesper Kjaer, Lars Mathiesen, Mike Youle, Christine Katlama, Andrew Hill, Johan N. Bruun, Nathan Clumeck, Pierre Dellamonica, Jens D. Lundgren, Antiviral Therapy, 11(6), 761(2006)

5. M.J. Koziel and M.G. Peters, The New England Journal of Medicine, 356, 14(2007), https://doi.org/10.1056/NEJMra065142

6. British National Formulary: BNF 69 (69 ed.), British Medical Association, p. 429(2015)

7. "Dolutegravir Sodium", drugs.com. (2019)

8. P. Geetha Swarupa, K. Lakshmana Rao, K. R. S. Prasad and K. Suresh Babu, Asian Journal of Pharmaceutical and Clinical Research, 9, 126(2016) 
RASĀYAN J. Chem.

Vol. 14 | No. 4 |2639-2644| October- December | 2021

9. D. Rambabu, B. Bhoomaiah, R.S.Ch. Phani and K. Balamurali Krishna, Pharmacophore, 2, 2(2011)

10. R.V. Athota, S. K. Jagarlapudi and M.R. Singampalli, Journal of Applied Pharmaceutical Science,7(3), 48(2017), https://doi.org/10.7324/JAPS.2017.70308

11. U. R. Mallu, V. R. Anna and B. B. Kasimala, Turkish Journal of Pharmaceutical Sciences, 16(4), 457(2019), https://doi.org/10.4274/tjps.galenos.2018.34635

12. P.S. Reddy, V.S.K. Jagarlapudi and C.B. Sekharan, Pharmaceutical Sciences, 22(1), 35(2016), https://doi.org/10.15171/PS.2016.07

13. R.S.C.H. Phani, K.R.S. Prasad, U.R. Mallu, Oriental Journal of Chemistry, 33(5), 2363(2017), http://dx.doi.org/10.13005/ojc/330528

14. K. Nekkala, J.V. Shanmukha Kumar and D. Ramachandran, Asian Journal of Pharmaceutical and Clinical Research, 11(2), 164(2018), https://doi.org/10.22159/ajpcr.2018.v11i2.22465

15. B. Prasanthi, J. Vijaya Ratna and R. S. Ch. Phani, Journal of Analytical Chemistry, 70, 1015(2015), https://doi.org/10.1134/S1061934815080146

16. R. S. Ch. Phani, K. R. S. Prasad and Useni Reddy Mallu, Der Pharma Chemica, 9, 20, (2017)

17. R. S. Ch. Phani, K. R. S. Prasad and Useni Reddy Mallu, Research Journal of Pharmacy and Technology, 10(12), 4264(2017), https://doi.org/10.5958/0974-360X.2017.00781.8

18. R. S. Ch. Phani, K. R. S. Prasad and Useni Reddy Mallu, Asian Journal of Chemistry, 29(11), 2565(2017), https://doi.org/10.14233/ajchem.2017.20899

19. Y.V. Sunil Kumar, U.R. Mallu and I.V. Kasi Viswanath, International Journal of Chem Tech Research, 69, 5(2016)

20. R. S. C. Phani, K.R.S. Prasad and R.M. Useni, Indian Drugs, 56(2), 31(2019)

21. Ch. Jaya Raju, T. Bhaskara Rao, P. Sanath Kumar Goud, J. Satish and K. Rajashekhar, Journal of Liquid Chromatography and Related Technologies, 41(17-18), 955(2018)

22. U.R. Mallu, V.R. Anna and B.B Kasimala, Indian drugs, 55(12), 41(2019)

23. K. Nekkala, J.V. Shanmukha Kumar, D. Ramachandran and G. Ramanaiah, Der Pharmacia Lettre, 8, 11(2016),

24. S.S. Prasad, B.B. Kasimala, V.R. Anna, Rasayan Journal of Chemistry, 14(4), 2183(2021), http://doi.org/10.31788/RJC.2021.1446426

25. R.S.C. Phani, K.R.S. Prasad and M. Useni Reddy, Oriental Journal of Chemistry, 32(2), 1139(2016), http://dx.doi.org/10.13005/ojc/320246

26. R.V. Athota, S.K. Jagarlapudi and M.R. Singampalli, International Journal of PharmTech Research, 9,7(2016),

27. R.S.C. Phani, U.R. Mallu, K.R.S Prasad, T. Mastnaiah, Rasayan Journal of Chemistry, 9, 4, (2016).

28. V S.K. Yelamanchi, U.R. Mallu, I.V. Kasi Viswanath, D. Balasubramanyam and G.N. Murthy, Oriental Journal of Chemistry, 32(5), 2297(2016), http://dx.doi.org/10.13005/ojc/320502

29. K.S. Girija, B.B. Kasimala, V.R. Anna, International Journal of Applied Pharmaceutics, 13(2), 165(2021), https://doi.org/10.22159/ijap.2021v13i2.39895

30. R.S.C. Phani, K.R.S. Prasad and Useni Reddy Mallu, International Journal of Pharma and Bio Sciences, 4(1), 440(2013)

31. Sambasivarao Vattikuti, R.S.C. Phani, R. Seetharaman, K. S. Lakshmi, IJPI's Journal of Analytical Chemistry, 1, 4(2011)

32. N. V. Krishnareddy, R.S.C Phani and R. Ramesh, International Journal of Research in Pharmacy and Biosciences, 2, 1(2011)

33. K. R. S. Prasad, V.D.N. Kumar Abbaraju, K. Uma Maheswar, Chaitanya Darapureddy and R.S.C. Phani, International Journal of Psychosocial Rehabilitation, 24(5), 3628(2020), https://doi.org/10.37200/IJPR/V24I5/PR202071

34. Raghavendra Rao Pasupuleti and Pei-Chien Tsai, Process Biochemistry, 102, 150(2021), https://doi.org/10.1016/j.procbio.2020.12.014

[RJC-6373/2021] 